\title{
Lipopolysaccharide-binding protein and CD14 are increased in the bronchoalveolar lavage fluid of smokers
}

\author{
V. Regueiro*,\#,+, M.A. Campos*,\#,+, P. Morey*,\#, J. Sauleda**\#, A.G.N. Agustíi,\#, , \\ J. Garmendia*,\# and J.A. Bengoechea*,\#
}

ABSTRACT: Lipopolysaccharide-binding protein (LBP) and CD14 contribute to the recognition of pathogens by cells, which triggers the activation of defence responses. Smoking is a risk factor for the development of chronic obstructive pulmonary disease (COPD) and respiratory infections. The current authors theorised that levels of LBP and CD14 in the lungs of smokers would be higher than those in the lungs of never-smokers. These elevated levels could affect host responses upon infection.

LBP, soluble CD14 (sCD14) and interleukin (IL)-8 were detected by ELISA. Nuclear factor (NF)$\kappa B$, p38 and the inhibitor ІкB $\alpha$ were studied by immunoassays. Gene expression was assessed by RT-PCR.

Bronchoalveolar lavage levels of LBP and CD14 were significantly higher in smokers and COPD patients than in never-smokers, whereas levels of both proteins were not significantly different between smokers and COPD patients. IL-6, IL-1 $\beta$ and cigarette smoke condensate induced the expression of LBP and CD14 by airway epithelial cells. LBP and SCD14 inhibited the nontypeable Haemophilus influenzae (NTHi)-dependent secretion of IL-8 and the activation of NF- $\mathrm{B}$ and p38 mitogen-activated protein kinase signalling pathways but they increased the internalisation of NTHi by airway epithelial cells.

Thus, in the inflamed airways of smokers both proteins could contribute to inhibit bacteriadependent cellular activation without compromising the internalisation of pathogens by airway cells.

KEYWORDS: CD14, Haemophilus influenzae, inflammation, lipopolysaccharide-binding protein

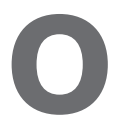

ne of the goals of the innate immune system is the rapid recognition of pathogens, which triggers the activation of host defence responses. Lipopolysaccharidebinding protein (LBP) and CD14 (either membrane-bound or soluble) contribute to the recognition of lipopolysaccharide (LPS) [1, 2].

LBP catalyses the transfer of LPS to membranebound CD14 (mCD14), which greatly amplifies the cellular response to LPS [3]. LBP can also transfer LPS to serum lipoproteins, which results in neutralisation of LPS-induced cellular response [1,2]. CD14 is also found in a soluble state (sCD14) [4] that has two opposite functions. Upon transfer of LPS by LBP, sCD14 mediates the activation of membrane-negative CD14 cells [5]. But sCD14 can also compete with mCD14 for LPS, thereby reducing LPS-triggered activities [1,
2]. It has also been shown that $\mathrm{sCD} 14$ strongly enhances the LBP-mediated transfer of LPS to serum lipoproteins $[1,2]$. Studies using knockout mice have shown that LBP and CD14 are important for clearing infections $[6,7]$.

Several studies have reported that serum levels of LBP and sCD14 increase in inflammatory conditions and there is a correlation between severity of disease and the levels of these proteins [8-12]. Some of these studies suggest that these increased levels of both proteins might amplify the cellular response to LPS and Gram-negative bacteria. However, it may well be that these levels are a host mechanism to blunt an overwhelming inflammatory reaction $[1,2]$.

Cigarette smoke is the main risk factor for the development of lung cancer and chronic obstructive

Earn CME accreditation by answering questions about this article. You will find these at the back of the printed copy of this issue or online at www.erj.ersjournals.com/current.shtml

AFFILIATIONS

${ }^{*}$ Centro Investigación Biomédica en Red Enfermedades Respiratorias, \#Program Infection and Immunity, Fundación Caubet-CIMERA IIles Balears, Bunyola,

"Servicio de Neumología, Hospital Universitari Son Dureta, Palma de Mallorca, Spain.

${ }^{+}$These authors contributed equally to the present study

CORRESPONDENCE

J.A. Bengoechea

Program Infection and Immunity, Fundació Caubet-CIMERA Illes Balears, Recinto Hospital Joan March, Carretera Sóller Km 12, 07110 Bunyola, Spain. Fax: 34971011797

E-mail: bengoechea@caubetcimera.es

Received

June 102008

Accepted after revision:

October 082008

\section{SUPPORT STATEMENT}

Fellowship support to M.A. Campos from the Govern Illes Balears (Palma Mallorca, Spain) is gratefully acknowledged. J. Garmendia is the recipient of a "Contrato de Investigador" from the Fondo de Investigación Sanitaria (FIS; Instituto de Salud Carlos III, Madrid, Spain). The present study has been funded by grants from FIS (CP0500027 and PI061251 to J. Garmendia and PI061629 to J.A. Bengoechea) and Govern Illes Balears (PRIB-200410075 and Grant for Competitive Groups to J.A. Bengoechea; llles Balears, Spain).

STATEMENT OF INTEREST None declared.

European Respiratory Journal Print ISSN 0903-1936 Online ISSN 1399-3003 
pulmonary disease (COPD) and it has been shown that exposure to cigarette smoke leads to lung inflammation [13]. Smoking is also one of the risk factors for respiratory infections [14]. In this context, the so-called British hypothesis states that recurrent bronchial infections are the reason, at least in part, that some smokers developed progressive airway obstruction and others do not [15]. It has been hypothesised that cigarette smoking may impair lung immune function against respiratory infections by, for example, affecting the recognition of pathogens and hence the activation of host defence mechanisms. Given the positive correlations between smoking and inflammation and between the latter and the levels of LBP and sCD14 [8-12], the present authors hypothesised that levels of these proteins in the lungs from smokers would be higher than those in lungs from never-smokers.

The current authors report that levels of LBP and sCD14 are increased in the bronchoalveolar lavage fluid (BALF) of smokers and COPD patients and that cigarette smoke or known inducers of acute-phase proteins activate the production of LBP and sCD14 by airway epithelial cells. Finally, the present authors have investigated whether LBP and sCD14 influence the cellular response to nontypeable Haemophilus influenzae (NTHi), a typical respiratory pathogen.

\section{METHODS}

\section{Population and ethics}

Participants (nine never-smokers, 10 smokers with normal lung function and 10 COPD patients, all male subjects) were recruited consecutively from the endoscopy unit of the Hospital Universitary Son Dureta (a tertiary referral hospital; Palma de Mallorca, Spain) from those requiring a bronchoscopy for the clinical evaluation of a solitary pulmonary nodule or haemoptysis. Participants gave their written consent after being fully informed of the nature, characteristics, risks and potential benefits of the current study, which had been approved previously by the Ethics Committee of the Hospital Universitari Son Dureta, Palma de Mallorca, Spain. COPD patients (six current smokers and four ex-smokers) were clinically stable and had not had an episode of exacerbation during the 3 months previous to the bronchoscopy. Six patients were being treated with inhaled steroids, but none were receiving oral steroid therapy. The present authors excluded individuals with other chronic lung diseases (asthma, bronchiectasis and interstitial lung diseases), atopy or cardiac, hepatic or renal failure. To avoid any potential effect of acute smoking, active smokers refrained from smoking for $12 \mathrm{~h}$ before bronchoscopy. This was confirmed by measuring the exhaled carbon monoxide concentration before bronchoscopy; it was found to be $<10 \mathrm{ppm}$ in all subjects.

\section{Lung function}

Forced spirometry was obtained in all participants. Spirometric reference values were those of a Mediterranean population [16].

\section{BALF}

BALF was obtained as previously described [17]. Differential cell counts were determined as described [17]. To investigate whether airways were colonised with bacteria, bronchial secretions were obtained using a protected specimen brush [17]. These were found to be culture negative in all cases.

\section{LBP, sCD14 and interleukin-8 determinations}

LBP and sCD14 levels were determined in the unconcentrated BALF after removing cells by centrifugation using ELISA kits (HyCult Biotechnology, Uden, the Netherlands). The sensitivity of the ELISAs for LBP and sCD14 are 4.4 and $2 \mathrm{ng} \cdot \mathrm{mL}^{-1}$, respectively. Interleukin (IL)-8 levels were also determined by ELISA (Endogen, Rockford, IL, USA) with a sensitivity of $<2 \mathrm{pg} \cdot \mathrm{mL}^{-1}$.

\section{Bacterial cultures}

An NTHi isolate, strain 157952, was donated by A. Oliver (Hospital Son Dureta, Palma de Mallorca, Spain). Bacteria were grown in agar chocolate plates (Biomerieux, Marcy l'Etolie, France) at $37^{\circ} \mathrm{C}$ and $5 \% \mathrm{CO}_{2}$. Bacteria were recovered in PBS and a cell suspension of $\sim 10^{9} \mathrm{cfu} \cdot \mathrm{mL}^{-1}$ was prepared in PBS and used as inoculum.

\section{Recombinant proteins}

Purified human LBP and sCD14 were purchased from HyCult Biotechnology and R\&D Systems (Minneapolis, MN, USA), respectively. Human IL-6, IL-1 $\beta$ and tumour necrosis factor (TNF)- $\alpha$ were obtained from Peprotech (Rocky Hill, NJ, USA).

\section{Cell cultures}

Monolayers of human lung carcinoma cells (A549; ATCC CCL185; ATCC, Manassas, VA, USA) and primary normal human bronchial epithelial cells (NHBE; Lonza, Basel, Switzerland) were grown as previously described [18]. A549 cells were serum starved for $18 \mathrm{~h}$ before infection. Prior to the experiment, A549 and NHBE cells were washed three times with PBS. Cell viability was assessed using trypan blue dye exclusion and was $>95 \%$ even $8 \mathrm{~h}$ post infection (with and without LBP and SCD14).

\section{Cytokine stimulation, adhesion and invasion assays}

A549 cells were infected at a multiplicity of infection of 100 bacteria per cell. For cytokine stimulation, after $6 \mathrm{~h}$ of infection, cells were washed three times with PBS, and then incubated with fresh medium containing gentamicin $\left(100 \mu \mathrm{g} \cdot \mathrm{mL}^{-1}\right)$ for a further $12 \mathrm{~h}$. Supernatants were carefully removed from the wells, cell debris was removed by centrifugation, and samples were frozen at $-80^{\circ} \mathrm{C}$. For the adhesion assays, cells were washed five times with PBS after $2 \mathrm{~h}$ of infection. Cells were lysed with $1 \%$ saponin in PBS and titred for viable counts of bacteria by plating on brain heart infusion agar plates supplemented with hemin $\left(10 \mu \mathrm{g} \cdot \mathrm{mL}^{-1}\right.$; Sigma Aldrich, St Louis, MO, USA) and nicotinamide adenine dinucleotide $\left(10 \mu \mathrm{g} \cdot \mathrm{mL}^{-1}\right.$; Sigma Aldrich). For the invasion assays, after $2 \mathrm{~h}$ of infection, monolayers were washed three times with PBS and then incubated for a further $1 \mathrm{~h}$ with fresh medium containing gentamicin $\left(100 \mu \mathrm{g} \cdot \mathrm{mL}^{-1}\right)$ to kill extracellular bacteria. Monolayers were washed three times with PBS, cells were lysed as previously described and titred for viable counts of intracellular bacteria. Experiments were carried out in triplicate on three independent occasions and results are expressed as \% invasion or adhesion $(100 \times$ number of bacteria recovered from well/initial number of bacteria added).

\section{Nuclear factor- $\kappa B$ assay}

Nuclear factor (NF)- $\kappa B$ activation was measured using the TransAM NFкB kit (Active Motif, Carlsbad, CA, USA). A549 cells seeded in 60-mm tissue culture dishes were infected for 
$1 \mathrm{~h}$. Cytoplasmic and nuclear extracts were obtained exactly as described by the manufacturer of the kit and the presence of activated NF- $\mathrm{KB}$ was determined exactly as recommended by the manufacturer using $15 \mu \mathrm{g}$ of protein. Results are presented as mean \pm SEM from three independent experiments.

\section{Immunoblots}

Cytoplasmic proteins $(15 \mu \mathrm{g})$ were separated by $10 \%$ SDSPAGE, electrotransferred to a nitrocellulose membrane and blocked with $3 \%$ skimmed milk in PBS. Immunostaining for the $N F-\kappa B$ inhibitory subunit, $I \kappa B \alpha$, was performed with polyclonal rabbit anti-IкB $\alpha$ antibody (Santa Cruz Biotechnology, Santa Cruz, CA, USA) whereas immunostaining for phosphorylated p38 was performed with polyclonal rabbit anti-phospho-p38 antibody (Cell Signaling, Danvers, MA, USA). Immunoreactive bands were visualised by incubation with conjugated-horseradish peroxidase swine anti-rabbit immunoglobulins (P0217; Dako, Glostrup, Denmark) using the SuperSignal West Dura system (Pierce, Rockford, IL, USA). Blots were reprobed with polyclonal anti-human tubulin, or anti-p38 to ensure that equal amounts of proteins were loaded in each lane.

\section{RT-PCR}

NHBE cells seeded in $60 \mathrm{~mm}$ tissue culture dishes were treated with the different stimuli for $24 \mathrm{~h}$. After treatment, cells were washed with PBS and total RNA was purified using a Nucleospin RNAII kit (Macherey-Nagel, Düren, Germany) as recommended by the manufacturer. cDNA was obtained by incubating $1 \mu \mathrm{g}$ of RNA with $1 \mathrm{mM}$ dNTPmix (Promega, Madison, WI, USA), $1 \mu \mathrm{L}$ of oligo-dT15 as primers (Promega), 20 units of RNasin (Promega), and 2.5 units of avian myeloblastosis virus reverse transcriptase (Promega) in a total volume of $20 \mu \mathrm{L}$ in the manufacturer's buffer (Promega) for $1 \mathrm{~h}$ at $42^{\circ} \mathrm{C}$ followed by $5 \mathrm{~min}$ at $99^{\circ} \mathrm{C}$ to inactivate the enzyme. PCR was performed using $10 \mu \mathrm{L}$ of cDNA as template and the following intron-spanning primers: human LBP (sense $5^{\prime}$ AGGGCCTGAGTCTCAGCATCT -3'; antisense 5'-CAGGCTGGCCGTGTTGAAGAC-3'); and human CD14 (sense 5'-ACTTATCGACCATGGAGC-3'; antisense 5'-AGGCATGGTGCCGGTTA-3'). Primers for human $\beta$-actin (sense 5'-GATGCCACAGGATTCCATACC-3'; antisense 5'-GAGCAAGAGAGGTATCCTGACC- $3^{\prime}$ ) were used as an internal control. For the detection of LBP the thermocycling protocol was as follows: 40 cycles of $94^{\circ} \mathrm{C}$ for $30 \mathrm{~s}, 57^{\circ} \mathrm{C}$ for $1 \mathrm{~min}, 72^{\circ} \mathrm{C}$ for $1 \mathrm{~min}$; whereas for the detection of CD14 the protocol was $94^{\circ} \mathrm{C}$ for $2 \mathrm{~min}$, followed by 35 cycles of denaturation at $98^{\circ} \mathrm{C}$ for $30 \mathrm{~s}$, annealing at $60^{\circ} \mathrm{C}$ for $10 \mathrm{~s}$ and extension at $72^{\circ} \mathrm{C}$ for $30 \mathrm{~min}$. For the detection of $\beta$-actin, only 30 cycles were applied, the annealing temperature was $60^{\circ} \mathrm{C}$ for $1 \mathrm{~min}$, and extension was $72{ }^{\circ} \mathrm{C}$ for $1 \mathrm{~min}$. Amplification products were resolved on a $1.5 \%$ agarose gel and recorded with a Gene Genius Bio imaging system (Syngene, Cambridge, UK) as jpeg files. They were exported to a computer for densitometry analysis using ImageJ software (available from the National Institute of Health http://rsb.info.nih.gov/ij/download.html). Bands were selected in each lane and analysed using the histogram analysis tool recording the mean. Results were expressed as a relative ratio of LBP or CD14 $(100 \times$ mean of gene/mean $\beta$-actin). cDNAs were obtained from three independent extractions of mRNA and each one was amplified by RTPCR on three independent occasions.

\section{Production of cigarette smoke condensate}

Cigarette smoke condensate (CSC) was prepared from commercial cigarettes $(0.8 \mathrm{mg}$ of nicotine, $10 \mathrm{mg}$ of tar and $10 \mathrm{mg}$ of $\mathrm{CO}$; Philip Morris, Madrid, Spain) as previously described with modifications [19]. Briefly, one cigarette was combusted using modified syringe apparatus that draws the smoke into a sterile glass containing $5 \mathrm{~mL}$ of tissue culture medium. In total, $10 \mathrm{~mL}$ of smoke was drawn within $10 \mathrm{~s}$ following a 30-s break. This process was repeated five times per cigarette. The CSC was filtered through a $0.22-\mu \mathrm{M}$ filter. The resulting solution was designated a $100 \%$ CSC solution and was used within $30 \mathrm{~min}$.

\section{Statistical analysis}

Results are expressed as mean \pm SEM. Differences between experimental groups were analysed by nonparametric twosided Mann-Whitney U-test or one-way ANOVA using Kruskal-Wallis contrasts as appropriate. A p-value $<0.05$ was considered significant.

\section{RESULTS}

\section{Clinical data}

Table 1 shows the clinical and functional data of subjects included in the study. COPD patients were slightly older than the other two groups. Cumulative smoking exposure was not significantly different between smokers with and without COPD. Lung function was normal in never-smokers and smokers without COPD whereas, by definition, patients with COPD had airflow obstruction (which was moderate to severe; table 1). The volume of BALF recovered was significantly lower in COPD patients than in never smokers, but total cell count was significantly higher in patients with COPD and smokers with normal lung function than in never-smokers (table 1). Differential cell counts were not different between groups (table 1).

\section{Levels of LBP and SCD14 are increased in BALF of smokers and COPD patients}

BALF levels of LBP (fig. 1a) and sCD14 (fig. 1b) were higher in smokers and COPD patients than in never-smokers whereas levels of both proteins were not significantly different in smokers and COPD patients (fig. 1). The levels of LBP correlated with the levels of $\mathrm{sCD} 14(\mathrm{r}=0.98, \mathrm{p}<0.05)$. There was not a significant correlation between the levels of LBP or SCD14 and BAL recovery and differential cell counts in any of the groups.

\section{Airway epithelial cells produce LBP and SCD14}

To investigate whether airway epithelial cells could be one of the sources of LBP and SCD14 found in the BALF of smokers and COPD patients, NHBE cells were incubated in the presence of IL- 6 and IL-1 $\beta$, known to stimulate the production of acute proteins [20, 21]. After $48 \mathrm{~h}$, IL-6 alone or in combination with IL-1 $\beta$ increased the levels of LBP in culture supernatants (fig. 2a), whereas both stimuli did not significantly increase the levels of sCD14 (fig. 2b). After $72 \mathrm{~h}$, the levels of LBP (fig. 2a) and sCD14 (fig. 2b) were significantly higher in culture supernatants from stimulated cells than in those from nonstimulated cells.

The current authors sought to determine whether CSC could stimulate the production of LBP and sCD14 by NHBE cells. 


\begin{tabular}{|c|c|c|c|}
\hline & Never-smokers & Smokers with normal lung function & COPD patients \\
\hline Age yrs & $56 \pm 5$ & $60 \pm 3$ & $64 \pm 2^{*}$ \\
\hline Smoking history pack-yrs & 0 & $37 \pm 5$ & $45 \pm 3$ \\
\hline $\mathrm{FEV}_{1}{ }^{\#} \%$ pred & $103 \pm 16$ & $98 \pm 10$ & $58 \pm 6^{*}$ \\
\hline Total cell count $10^{3} \cdot \mathrm{mL}^{-1}$ & $65.6 \pm 17.6$ & $271 \pm 58^{*}$ & $182 \pm 33^{*}$ \\
\hline Macrophages \% & $92 \pm 1$ & $92 \pm 2$ & $85 \pm 3$ \\
\hline Lymphocytes \% & $7 \pm 1$ & $7 \pm 2$ & $9 \pm 2$ \\
\hline Neutrophils \% & $1 \pm 0.4$ & $1 \pm 0.2$ & $3 \pm 2$ \\
\hline BALF recovery $m$ & $105 \pm 7$ & $94 \pm 4$ & $70 \pm 7^{\star}$ \\
\hline
\end{tabular}

Data are presented as mean \pm SEM, unless otherwise stated. COPD: chronic obstructive pulmonary disease; FEV 1 : forced expiratory volume in one second; \% pred: \% predicted; FVC: forced vital capacity. ${ }^{\#}$ : measured after bronchodilation. *: $p<0.05$ versus never-smokers.

After $48 \mathrm{~h}$, both 2.5 and 5\% CSC increased the levels of LBP significantly but not the levels of sCD14 (fig. 2). After $72 \mathrm{~h}$, both amounts of CSC increased the levels of LBP and SCD14 (fig. 2). The levels of LBP and sCD14 induced by 5\% CSE were significantly higher than those induced by $2.5 \%$ CSE $(p<0.05$; fig. 2).

To determine whether the increased protein levels were paralleled by elevated levels of mRNA, semi-quantitative RTPCR analyses were carried out. IL-6, alone and in combination with IL-1 $\beta$, increased mRNA levels of the $l b p$ and $c d 14$ genes (fig. 2c). CSE also increased the levels of $l b p$ and $c d 14$; the effect of $5 \%$ CSE was higher than that of $2.5 \%$ CSE. Densitometric analysis confirmed these results (fig. 2d).

\section{LBP and SCD14 inhibit the cellular response to NTHi}

NTHi is a pathogen that is frequently isolated from the airways of smokers and COPD patients and it induces the activation of an inflammatory programme by airway epithelial cells [22]. The present authors investigated the effect of LBP and sCD14 on the activation of NHBE and A549 cells by NTHi. In the presence of LBP, the amount of IL- 8 secreted by infected NHBE cells was reduced (fig. 3a). Likewise, NTHi-induced IL-8 secretion was also reduced in the presence of SCD14 (fig. 3a). A combination of both proteins (LBP and sCD14) had the strongest effect (fig. 3a). Similar results were obtained when A549 cells were used (fig. 3b). Neither LBP nor sCD14 alone or both together induced the secretion of IL- 8 by NHBE or A549 cells (data not shown). To rule out a nonspecific effect of LBP and SCD14 on the activation of NHBE cells, the current authors investigated whether both proteins affect IL- 8 production induced by TNF- $\alpha$. The amount of IL- 8 secreted by NHBE in response to TNF- $\alpha$ (final concentration of $100 \mathrm{ng} \cdot \mathrm{mL}^{-1}$ ) was independent of the presence of LBP and sCD14 (both used together at a final concentration of $100 \mu \mathrm{g} \cdot \mathrm{mL}^{-1}$; amount of IL-8 induced by TNF- $\alpha$ in the absence or presence of both proteins was $993 \pm 25$ and $1,084 \pm 90 \mathrm{pg} \cdot \mathrm{mL}^{-1}$, respectively; $\left.\mathrm{p}>0.05\right)$.

It has been shown that activation of NF- $\mathrm{B}$ by NTHi is necessary for IL-8 secretion by epithelial cells [22]. The present
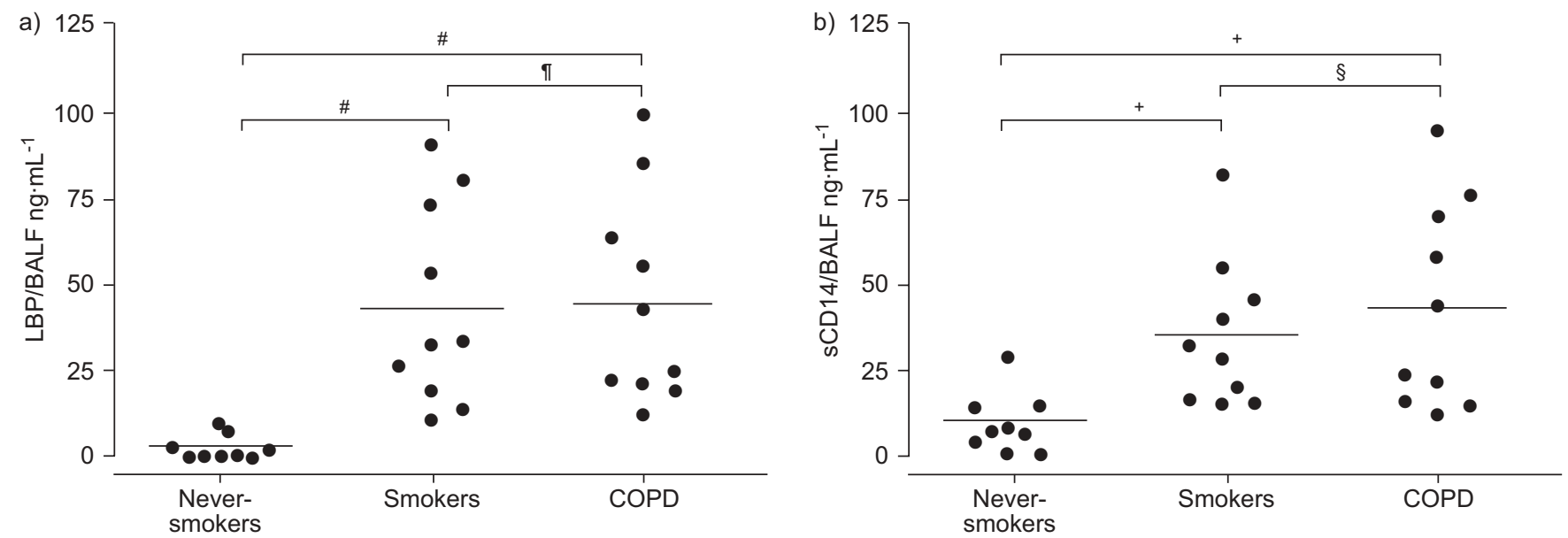

FIGURE 1. Analysis of the concentrations of a) lipopolysaccharide-binding protein (LBP) and b) soluble CD14 (SCD14) in unconcentrated bronchoalveolar fluid (BALF) from never-smokers $(n=9)$, smokers $(n=10)$ and chronic obstructive pulmonary disease (COPD) patients $(n=10)$. The results were analysed by one-way ANOVA using Kruskal-Wallis contrasts. $p<0.05$ was considered significant. ${ }^{*}: p=0.001 ;{ }^{\bullet}: p=0.280 ;{ }^{+}: p=0.002 ;{ }^{\S}: p=0.739$ 

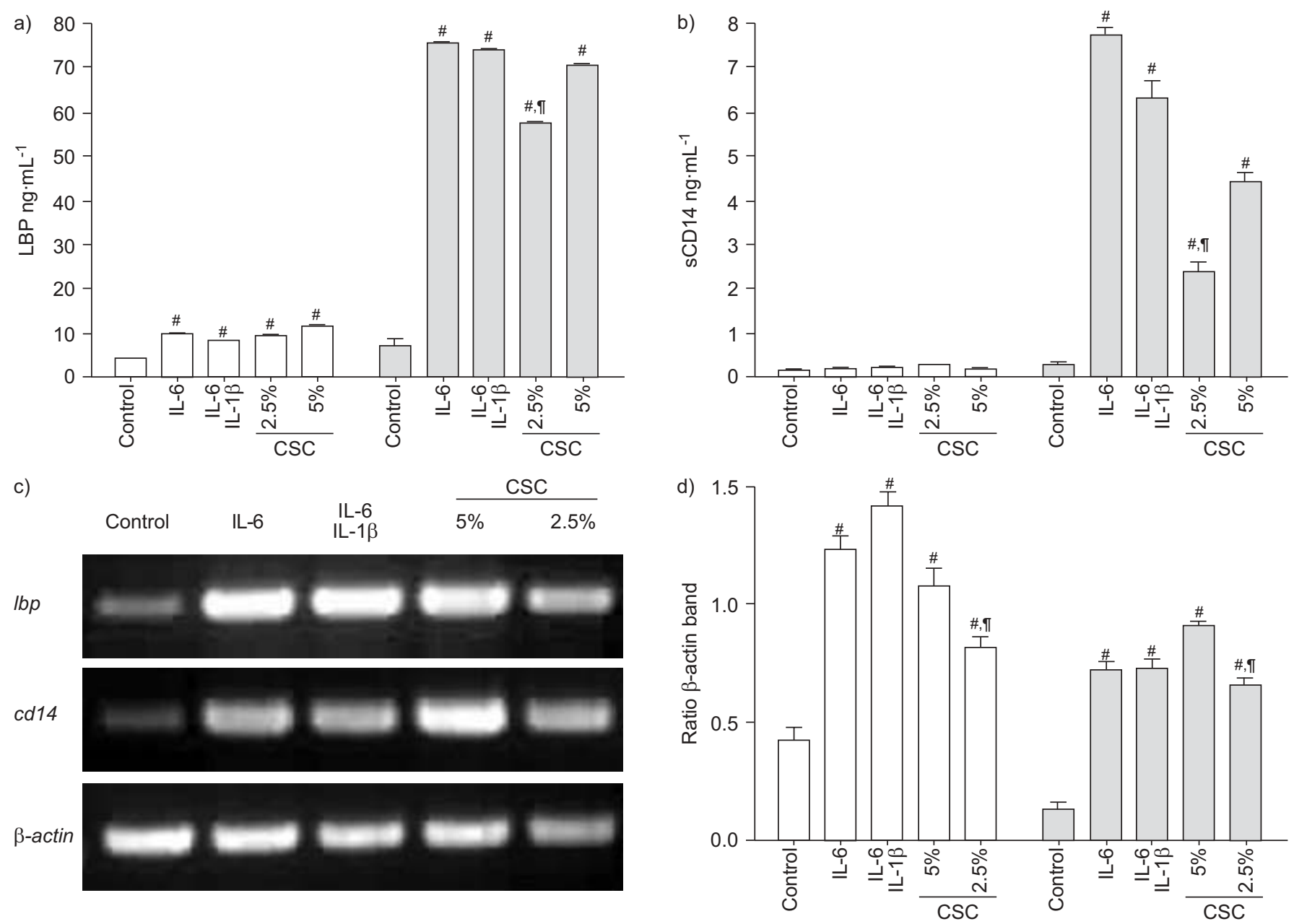

FIGURE 2. Analysis of the concentrations of a) lipopolysaccharide-binding protein (LBP) and b) soluble CD14 (sCD14) secreted by normal human bronchial epithelial

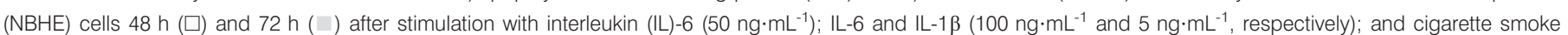
condensate (CSC; 2.5 and $5 \%$ final concentrations). The results were analysed by one-way ANOVA using Kruskal-Wallis contrasts. c) Analysis by RT-PCR of mRNA levels of the Ibp and cd14 genes from NHBE cells treated with IL-6 (50 ng. $\left.\mathrm{mL}^{-1}\right)$; IL-6 and IL-1 $\beta$ (100 and $5 \mathrm{ng} \cdot \mathrm{mL}^{-1}$, respectively) and CSC (2.5 and $5 \%$ final concentrations) for $24 \mathrm{~h}$. d) Densitometry analysis of gels (samples were obtained from three independent extractions of mRNA and each one was amplified by RT-PCR on three independent occasions). LBP: $\square$; CD14: $1{ }^{*}{ }^{*}: p<0.05$ versus nontreated cells; ${ }^{\top}: p<0.05$ versus treated cells with $5 \%$ CSC.

authors investigated whether LBP and sCD14 would affect NF$\kappa \mathrm{B}$ activation upon the infection of A549 cells by NTHi. Cellular lysates prepared from infected cells in the presence or absence of LBP and sCD14 were analysed using an NF- $\kappa B$ ELISA. Lysates from infected cells in the presence of LBP and SCD14 yielded lower amounts of active NF- $\kappa$ B than lysates from infected cells absent of LBP and SCD14, and this amount was similar to that of noninfected cells (fig. 4a). One of the major pathways for NF- $\mathrm{\kappa B}$ activation involves the phosphorylation of $I \kappa B \alpha$ followed by degradation of the protein thereby allowing the migration of NF- $\mathrm{BB}$ dimers to the nucleus. The expression of I $\mathrm{K} \mathrm{B} \alpha$ was analysed in cytoplasmic extracts by immunoblot analysis. I $\mathrm{\kappa} \mathrm{\alpha} \alpha$ degradation was apparent in infected cells but absent if infection occurred in the presence of LBP and sCD14 (fig. 4b).

p38 mitogen-activated protein (MAP) kinase is also involved in NTHi-dependent secretion of IL-8 by epithelial cells [22]. The current authors studied whether LBP and sCD14 would affect p38 MAP kinase activation upon infection of A549 cells by NTHi. Figure $4 \mathrm{c}$ shows that LBP and SCD14 inhibited the NTHiinduced phosphorylation of p38 MAP kinase. Altogether, the data show that LBP and sCD14 decrease the ability of NTHi to stimulate a cell inflammatory response.

\section{LBP and SCD14 increase the adhesion and internalisation of NTHi}

The present authors sought to determine whether both proteins modified the interaction between NTHi and airway epithelial cells. LBP or sCD14 alone did not alter the adhesion of NTHi to A549 cells (fig. 5a) whereas both proteins (present at $100 \mathrm{ng} \cdot \mathrm{mL}^{-1}$ ) increased the adhesion of NTHi to A549 cells. The effect of LBP and sCD14 on NTHi internalisation by A549 cells was also studied. Overall, $100 \mathrm{ng} \cdot \mathrm{mL}^{-1}$ of LBP plus sCD14 significantly increased the number of intracellular NTHi recovered (fig. 5b). 

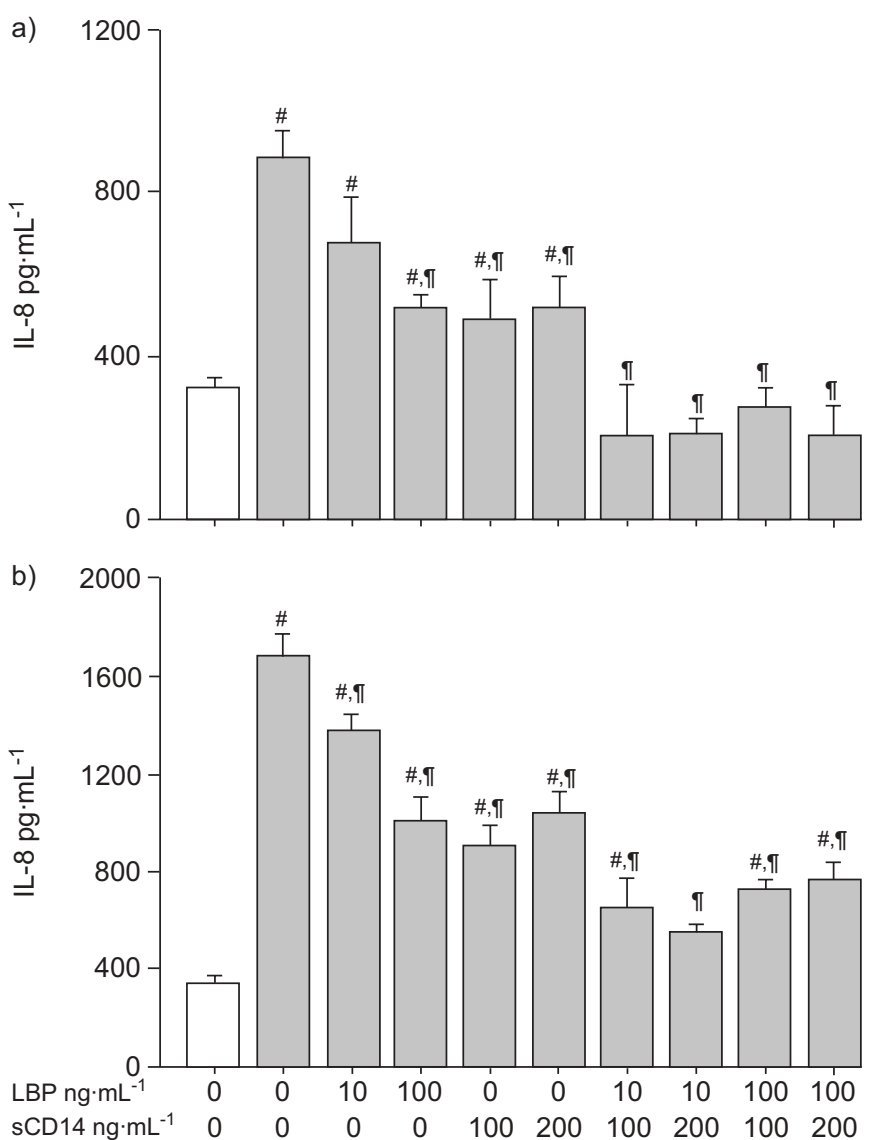

FIGURE 3. Levels of a) interleukin (IL)-8 secreted to the culture medium by normal human bronchial epithelial (NHBE) cells and b) A549 cells infected ( $\square$ ) or not infected $(\square)$ with nontypeable Haemophilus influenza in the absence or presence of different concentrations of lipopolysaccharide-binding protein (LBP) and soluble CD14 (sCD14). The results were analysed by one-way ANOVA using Kruskal-Wallis

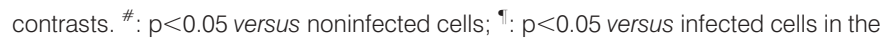
absence of LBP and SCD14.

\section{DISCUSSION}

The main findings of the current study are: 1) LBP and sCD14 levels are increased in the BALF of smokers with and without COPD; 2) airway epithelial cells in culture produce LBP and SCD14 in response to stimulation by cytokines and CSC; and 3) LBP and SCD14 decrease the ability of NTHi to stimulate an inflammatory response while facilitating its adhesion and internalisation by airway epithelial cells.

Previous studies have shown the presence of LBP and SCD14 in the airways of healthy subjects $[12,23]$. Moreover, evidence indicates that LBP and SCD14 levels increase in patients with lung diseases $[8,12,23]$ yet, to the best of the present authors' knowledge, the current study is the first showing elevated levels of both molecules in smokers. The fact that the levels of LBP and sCD14 were not significantly different between smokers and COPD patients suggests that both proteins might not play an important role in the development of COPD. However, further studies should be carried out to rigorously rule out any participation of these molecules in the pathogenesis of COPD. Hepatocytes are considered the main source of circulating LBP and sCD14 [1]. In fact, the amount of LBP and
sCD14 in human serum increases severalfold during acute response [1]. Therefore, accumulation of both proteins in the airway may be caused by extravasation from vascular compartments or by local production; these explanations are not mutually exclusive. The results of the current study support the latter because IL- 6 and IL-1 $\beta$, known inducers of acute phase proteins $[20,21]$, were shown to up-regulate the expression of both proteins. Similar results have been published for LBP [24] but, to the current authors' knowledge, the present study is the first to describe that airway epithelial cells can express sCD14. Considering that IL-6 and IL-1 $\beta$ are increased in the airways of smokers [13], it was proposed that both cytokines may stimulate airway epithelial cells to produce LBP and sCD14 in vivo, thereby accounting, at least in part, for the elevated levels of both proteins in the airways of smokers. Mechanistically, human promoter regions of LBP and CD14 contain binding sites for activator protein (AP)-1, CCAAT/ enhancer binding protein and acute-phase reactants (APRE)/ signal transducers and activators of transcription (STAT)-3 [25, 26] and both cytokines are known to activate these signalling pathways [27, 28]. The current study showed that CSE also induced the expression of LBP and sCD14. The molecular mechanism responsible for this is currently unknown. It is known that CSE activates AP-1 and STAT-3 signalling pathways [29], which are involved in the expression of LBP and sCD14 $[25,26]$. The present authors cannot rigorously rule out a paracrine mechanism via the induction of cytokine expression. However, neither IL-6 nor IL-1 $\beta$ were detected in the supernatants of CSE-treated cells (data not shown).

An important question is: what could the biological meaning of these high levels of LBP and sCD14 in the airways be? The classical vision states that LBP transfers pathogen-associated molecular patterns (PAMPs) to CD14 to facilitate cellular defence responses $[1,2]$. In turn, high levels of both molecules would prone the host to develop an overwhelming inflammatory response leading to complications such as septic shock and acute respiratory distress syndrome $[1,2]$.

In contrast, high levels of LBP and SCD14 are associated with an inhibitory effect on cellular activation by bacterial components [1]. This is considered a host defence mechanism to blunt an otherwise fierce inflammatory response [1, 2]. Currently discussed explanations are the ability of LBP to transfer bacterial PAMPs to serum lipoproteins, which is greatly enhanced by sCD14 resulting in the neutralisation of the bioactivity of the bacterial molecules [30]. The prevailing vision postulates that the balance of cellular responses against PAMPs is modulated by the levels of LBP and SCD14.

The present authors have shown that LBP and sCD14, alone and in combination, reduced NTHi-dependent IL-8 secretion by airway epithelial cells. Intact live bacteria were chosen instead of dead bacteria or purified PAMPs, such as LPS, to reflect NTHi-airway epithelial cell interaction which is the likely in vivo scenario. In fact, it has been shown that purified LPS from NTHi does not recapitulate the cellular response induced by whole bacteria in NHBE cells [31]. NTHi-induction of IL- 8 secretion is dependent on the activation of NF- $\kappa B$ and p38 MAP kinase signalling pathways [22]. The current authors hypothesised that LBP and sCD14 could downregulate the stimulation of these pathways by NTHi. The present results 


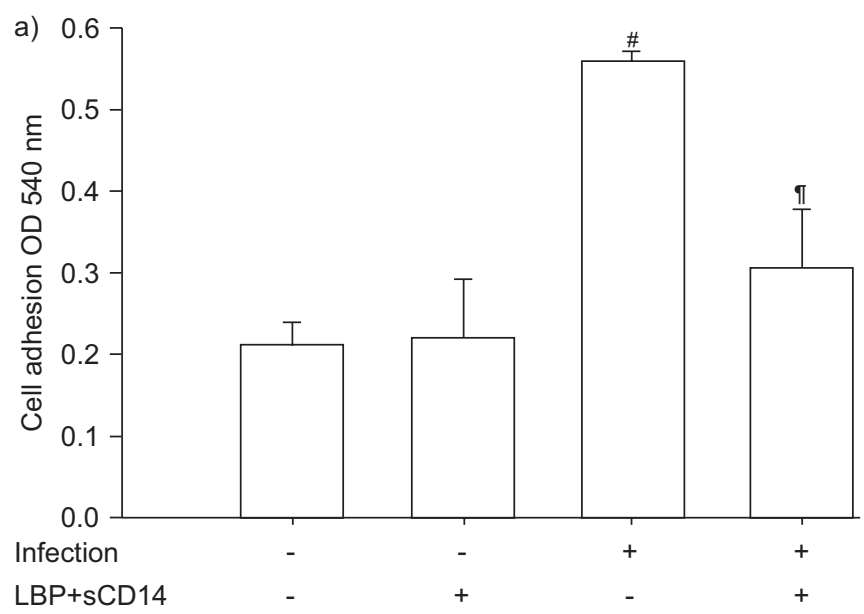

c)
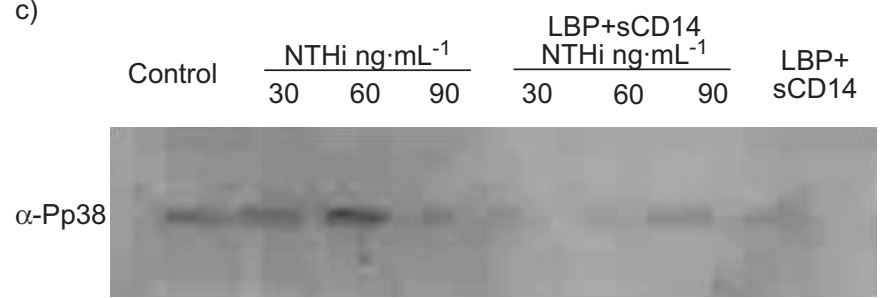

$\alpha-p 38$

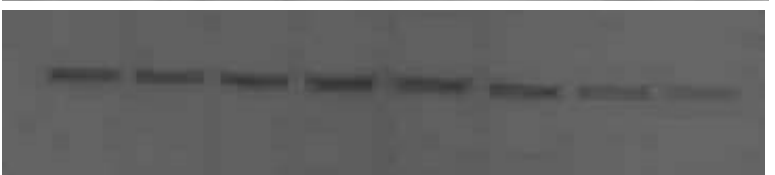

showed that both proteins inhibited the NTHi-dependent activation of $\mathrm{NF}-\kappa \mathrm{B}$ by affecting $\mathrm{I} \kappa \mathrm{B} \alpha$ degradation. Both proteins also abrogated the NTHi-dependent phosphorylation of p38MAP kinase. Of note in the current study the inhibition of cellular activation was not caused by a reduction in the number of adherent or internalised bacteria. Conversely, high levels of LBP and sCD14 increased the percentage of adherent and intracellular bacteria. Importantly, in the case of NTHi, it has been clearly shown that there is no correlation between

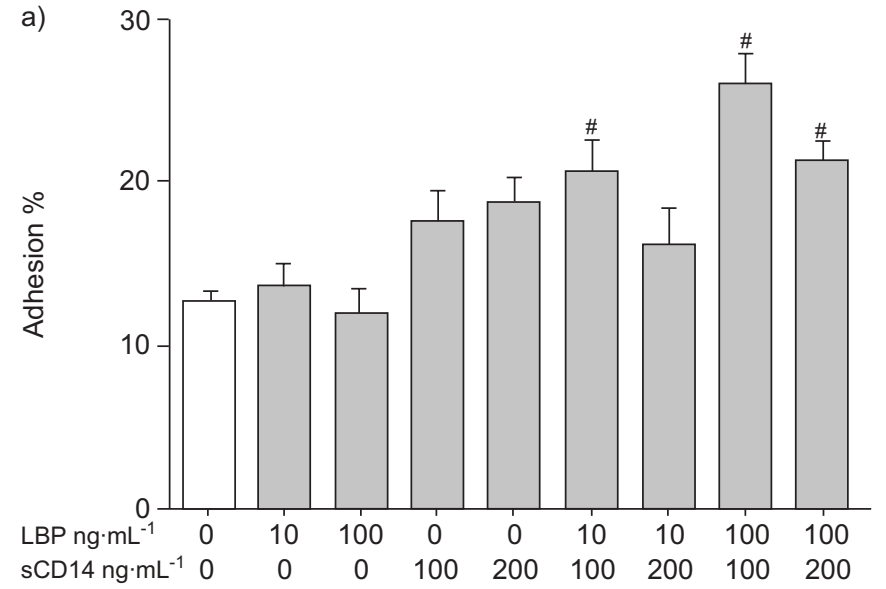

b)

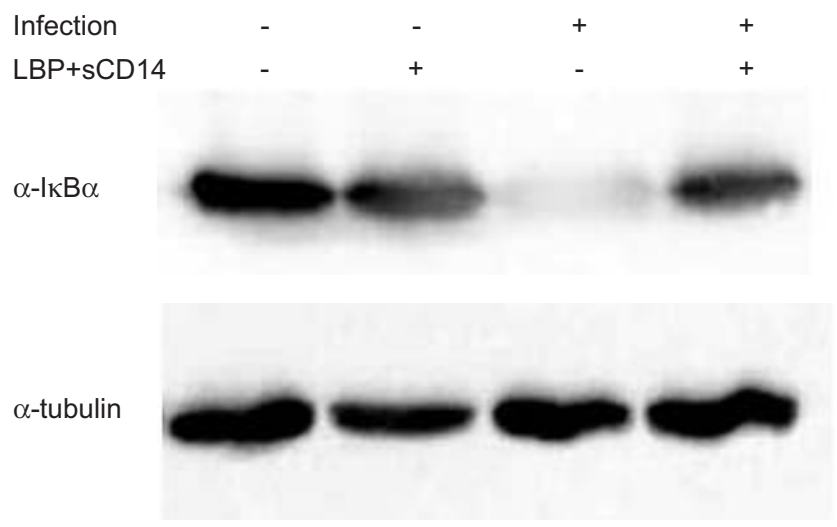

FIGURE 4. Lipopolysaccharide-binding protein (LBP; $100 \mathrm{ng} \cdot \mathrm{mL}^{-1}$ ) and sCD14 (100 ng. $\mathrm{mL}^{-1}$ ) reduce the nontypeable Haemophilus influenzae (NTHi)dependent activation of nuclear factor (NF)- $\mathrm{KB}$ and mitogen-activated protein (MAP) kinase p38 pathways. a) LBP and SCD14 reduce the NTHi-dependent translocation of NF-KB to the nuclei of A549 cells. b) Upper panel of the immunoblot: the NF- $\mathrm{KB}$ inhibitory subunit $(\mathrm{I} \mathrm{KB} \alpha)$ levels in cytoplasmic extracts of A549 cells infected with NTHi for $1 \mathrm{~h}$ in the absence or presence of LBP and soluble CD14 (sCD14). Lower panel of the immunoblot: tubulin levels under the same conditions. The results are representative of four independent experiments. c) Immunoblots showing phospho-p38 ( $\alpha$-Pp38) and total p38 levels in cytoplasmic extracts of A549 cells infected with NTHi for different time-points (30-90 min) in the absence or presence of LBP and SCD14. The results are representative of four independent experiments. ${ }^{*}$ : $p<0.05$ versus noninfected cells; " $p<0.05$ versus infected cells.

bacterial adhesion and the activation of airway epithelial cells $[31,32]$ and therefore, it was not unexpected that the increased uptake of NTHi by airway cells was not associated with greater cell response.

One potential limitation of the current study deserves some discussion. It would be of interest to compare the production of LBP and sCD14 by primary airway epithelial cells from smokers versus never-smokers. To this end, tissue samples

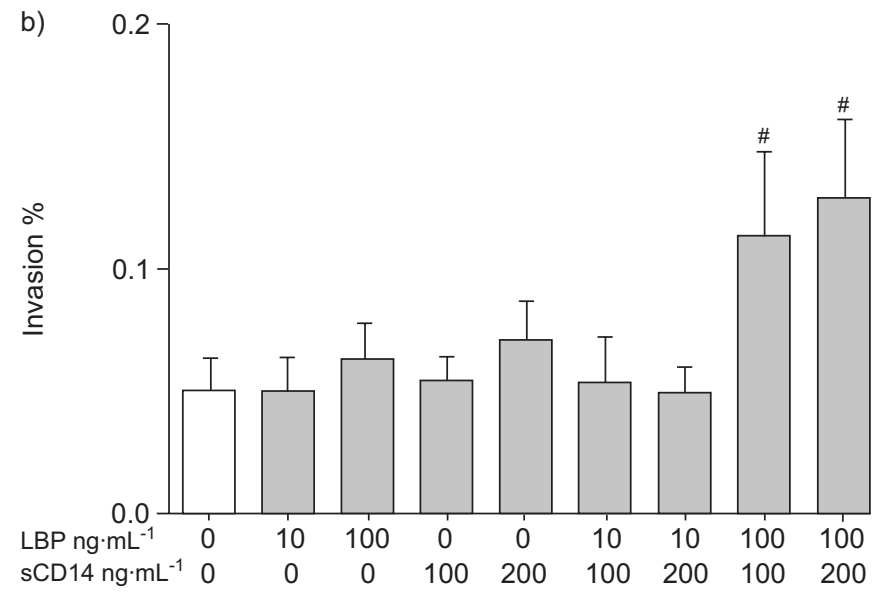

FIGURE 5. a) Lipopolysaccharide-binding protein (LBP) and soluble CD14 (sCD14) enhance the adhesion and b) internalisation of NTHi by A549 cells. All cells were infected. $\square:$ : LBP and/or SCD14; $\square$ : control. ${ }^{\#}$ : significant difference $(\mathrm{p}<0.05)$ from infected cells in the absence of LBP and sCD14. 
should be obtained by a surgical procedure and the expression of molecules analysed by immunohistochemistry. However, the current authors have shown that stimuli widely accepted to be present in the airways of smokers and COPD patients did stimulate the production of LBP and sCD14 by NHBE.

Based on the present data and on all the summarised evidence, the current authors propose that the high levels of lipopolysaccharide-binding protein and soluble CD14 found in the airways of smokers could be one of the host mechanisms contributing to prevent an overwhelming inflammatory response caused by smoking and the constant exposure of airways to bacteria and pathogen-associated molecular patterns. Thus, both proteins could contribute to reduce the bacteria and pathogen-associated molecular patterns-induced inflammatory response without compromising the internalisation of pathogens by airway cells. Future studies will aim to clarify all these issues.

\section{ACKNOWLEDGEMENTS}

The present authors are grateful to members of the Bengoechea laboratory (Bunyola, Spain) for helpful discussions.

\section{REFERENCES}

1 Van Amersfoort ES, Van Berkel TJ, Kuiper J. Receptors, mediators, and mechanisms involved in bacterial sepsis and septic shock. Clin Microbiol Rev 2003; 16: 379-414.

2 Zweigner J, Schumann RR, Weber JR. The role of lipopolysaccharide-binding protein in modulating the innate immune response. Microbes Infect 2006; 8: 946-952.

3 Wright SD, Ramos RA, Tobias PS, Ulevitch RJ, Mathison JC. CD14, a receptor for complexes of lipopolysaccharide (LPS) and LPS binding protein. Science 1990; 249: 1431-1433.

4 Bas S, Gauthier BR, Spenato U, Stingelin S, Gabay C. CD14 is an acute-phase protein. J Immunol 2004; 172: 4470-4479.

5 Pugin J, Schurer-Maly CC, Leturcq D, Moriarty A, Ulevitch RJ, Tobias PS. Lipopolysaccharide activation of human endothelial and epithelial cells is mediated by lipopolysaccharidebinding protein and soluble CD14. Proc Natl Acad Sci USA 1993; 90: 2744-2748.

6 Jack RS, Fan X, Bernheiden M, et al. Lipopolysaccharidebinding protein is required to combat a murine gramnegative bacterial infection. Nature 1997; 389: 742-745.

7 Yang KK, Dorner BG, Merkel U, et al. Neutrophil influx in response to a peritoneal infection with Salmonella is delayed in lipopolysaccharide-binding protein or CD14deficient mice. J Immunol 2002; 169: 4475-4480.

8 Martin TR, Rubenfeld GD, Ruzinski JT, et al. Relationship between soluble CD14, lipopolysaccharide binding protein, and the alveolar inflammatory response in patients with acute respiratory distress syndrome. Am J Respir Crit Care Med 1997; 155: 937-944.

9 Opal SM, Scannon PJ, Vincent JL, et al. Relationship between plasma levels of lipopolysaccharide (LPS) and LPS-binding protein in patients with severe sepsis and septic shock. J Infect Dis 1999; 180: 1584-1589.

10 Takeshita S, Nakatani K, Tsujimoto H, Kawamura Y, Kawase H, Sekine I. Increased levels of circulating soluble CD14 in Kawasaki disease. Clin Exp Immunol 2000; 119: 376-381.
11 Yu S, Nakashima N, Xu BH, et al. Pathological significance of elevated soluble CD14 production in rheumatoid arthritis: in the presence of soluble CD14, lipopolysaccharides at low concentrations activate RA synovial fibroblasts. Rheumatol Int 1998; 17: 237-243.

12 Ward C, Walters EH, Zheng L, Whitford H, Williams TJ, Snell GI. Increased soluble CD14 in bronchoalveolar lavage fluid of stable lung transplant recipients. Eur Respir J 2002; 19: 472-478.

13 Barnes PJ. New concepts in chronic obstructive pulmonary disease. Annu Rev Med 2003; 54: 113-129.

14 Ruiz M, Ewig S, Marcos MA, et al. Etiology of communityacquired pneumonia: impact of age, comorbidity, and severity. Am J Respir Crit Care Med 1999; 160: 397-405.

15 Fletcher CM. Chronic bronchitis. Its prevalence, nature, and pathogenesis. Am Rev Respir Dis 1959; 80: 483-494.

16 Roca J, Sanchis J, Agusti-Vidal A, et al. Spirometric reference values from a Mediterranean population. Bull Eur Physiopathol Respir 1986; 22: 217-224.

17 Barcelo B, Pons J, Fuster A, et al. Intracellular cytokine profile of $\mathrm{T}$ lymphocytes in patients with chronic obstructive pulmonary disease. Clin Exp Immunol 2006; 145: 474-479.

18 Regueiro V, Campos MA, Pons J, Alberti S, Bengoechea JA. The uptake of a Klebsiella pneumoniae capsule polysaccharide mutant triggers an inflammatory response by human airway epithelial cells. Microbiology 2006; 152: 555-566.

19 Witherden IR, Vanden Bon EJ, Goldstraw P, Ratcliffe C, Pastorino U, Tetley TD. Primary human alveolar type II epithelial cell chemokine release: effects of cigarette smoke and neutrophil elastase. Am J Respir Cell Mol Biol 2004; 30: 500-509.

20 Baumann H, Gauldie J. Regulation of hepatic acute phase plasma protein genes by hepatocyte stimulating factors and other mediators of inflammation. Mol Biol Med 1990; 7: 147-159.

21 Dinarello CA. Interleukin-1 and the pathogenesis of the acute-phase response. N Engl J Med 1984; 311: 1413-1418.

22 Li JD. Exploitation of host epithelial signaling networks by respiratory bacterial pathogens. J Pharmacol Sci 2003; 91: 1-7.

23 Dubin W, Martin TR, Swoveland P, et al. Asthma and endotoxin: lipopolysaccharide-binding protein and soluble CD14 in bronchoalveolar compartment. Am J Physiol 1996; 270: L736-L744.

24 Dentener MA, Vreugdenhil AC, Hoet PH, et al. Production of the acute-phase protein lipopolysaccharide-binding protein by respiratory type II epithelial cells: implications for local defense to bacterial endotoxins. Am J Respir Cell Mol Biol 2000; 23: 146-153.

25 Moeenrezakhanlou A, Nandan D, Shephard L, Reiner NE. $1 \alpha, 25$-dihydroxycholecalciferol activates binding of CREB to a CRE site in the CD14 promoter and drives promoter activity in a phosphatidylinositol-3 kinase-dependent manner. J Leukoc Biol 2007; 81: 1311-1321.

26 Schumann RR, Kirschning CJ, Unbehaun A, et al. The lipopolysaccharide-binding protein is a secretory class 1 acute-phase protein whose gene is transcriptionally activated by APRF/STAT/3 and other cytokine-inducible nuclear proteins. Mol Cell Biol 1996; 16: 3490-3503.

27 Heinrich PC, Behrmann I, Haan S, Hermanns HM, MullerNewen G, Schaper F. Principles of interleukin (IL)-6-type 
cytokine signalling and its regulation. Biochem J 2003; 374: $1-20$.

28 Stylianou E, Saklatvala J. Interleukin-1. Int J Biochem Cell Biol 1998; 30: 1075-1079.

29 Rahman I. Regulation of nuclear factor- $\kappa$ B, activator protein- 1 , and glutathione levels by tumor necrosis factor- $\alpha$ and dexamethasone in alveolar epithelial cells. Biochem Pharmacol 2000; 60: 1041-1049.

30 Wurfel MM, Hailman E, Wright SD. Soluble CD14 acts as a shuttle in the neutralization of lipopolysaccharide (LPS) by
LPS-binding protein and reconstituted high density lipoprotein. J Exp Med 1995; 181: 1743-1754.

31 Clemans DL, Bauer RJ, Hanson JA, et al. Induction of proinflammatory cytokines from human respiratory epithelial cells after stimulation by nontypeable Haemophilus influenzae. Infect Immun 2000; 68: 4430-4440.

32 Frick AG, Joseph TD, Pang L, Rabe AM, St Geme JW III, Look DC. Haemophilus influenzae stimulates ICAM-1 expression on respiratory epithelial cells. J Immunol 2000; 164: 4185-4196. 